\title{
Recurrent odontogenic ghost cell carcinoma (OGCC) at a reconstructed fibular flap: A case report with immunohistochemical findings
}

\author{
Bo-Han Li ${ }^{1}$, Young-Ah Cho ${ }^{2}$, Soung-Min Kim ${ }^{1}$, Myung-Jin Kim ${ }^{1}$, Sam-Pyo Hong ${ }^{2}$, Jong-Ho Lee ${ }^{1,3}$ \\ ${ }^{1}$ Department of Oral \& Maxillofacial Surgery, School of Dentistry, Seoul National University \\ ${ }^{2}$ Department of Oral Pathology, School of Dentistry, Seoul National University \\ ${ }^{3}$ Dental Research Institute, School of Dentistry, Seoul National University
}

Correspondence:

Department of Oral \& Maxillofacial Surgery

Seoul National University Dental Hospital

275-1 Yeongeon-dong, Jongno-gu

Seoul, \#110-749, Korea

leejongh@snu.ac.kr

Li BH, Cho YA, Kim SM, Kim MJ, Hong SP, Lee JH. Recurrent odontogenic ghost cell carcinoma (OGCC) at a reconstructed fibular flap: A case report with immunohistochemical findings. Med Oral Patol Oral Cir Bucal. 2011 Aug 1;16 (5):e651-6.

http://www.medicinaoral.com/medoralfree01/v16i5/medoralv16i5p651.pdf

Received: 09/03/2010

Accepted: 23/04/2010

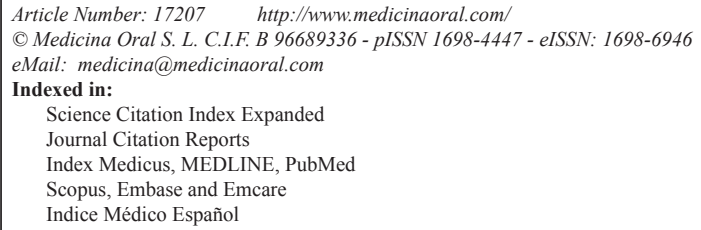

\begin{abstract}
Odontogenic ghost cell carcinoma (OGCC), a malignant counterpart of the odontogenic ghost cell tumor (OGCT), with aggressive growth characteristics, is exceedingly rare. A painful swelling in the jaw with local paresthesia is the most common symptom.

We described a case of 47-year Korean woman who had a rare central epithelial odontogenic ghost cell carcinoma which recurred at reconstructed fibular flap. Immunohistochemical differences between OGCT and OGCC analyzed using primary and recurred surgical specimen. On the basis of this case, the tumor started as an OGCT and transformed into OGCC with highly aggressive, rapidly growing, infiltrative tumors. Our findings suggest that some of the cytokines produced by ghost cells may play important roles in causing extensive bone resorption in the odontogenic ghost cell carcinoma.

Wide local excision with histologically clean margins is the treatment mode of selection. Also, we recommend close long-term surveillance of OGCT because of high recurrence and potential for malignancy transformation.
\end{abstract}

Key words: Odontogenic ghost cell carcinoma (OGCC), odontogenic ghost cell tumor (OGCT), malignant transformation, immunohistochemical finding.

\section{Introduction}

Odontogenic ghost cell carcinoma (OGCC) is a rare malignant odontogenic epithelial tumor with features of calcifying odontogenic cysts (COCs) $(1,2)$. Until now, only 26 OGCCs have been reported in the English language literature (3). In addition, OGCC can be further divided into two sub-classes, odontogenic central epithelial ghost cell carcinoma (OCEGCC) and odontogenic peripheral epithelial ghost cell carcinoma (OPEGCC). Here, we report a recurrent case of OCEGCC at mandible which has been previously reconstructed with fibular flap and describe its clinicoimmunohistochemical features. 


\section{Case Report}

\section{Clinical features and hospital course}

A 47-year-old Korean woman visited our department because of a slow-growing, painful and swelling mass in her right mandible six years ago (Sep 10, 2003). Clinical examination revealed an ill- defined, hard mass in the right mandibular body extending from right submandibular to the submental space without surface ulceration. At the time of visit, she had high fever and marked oral swelling. Panorama showed central bone destruction from right first premolar to wisdom tooth. At CT and rapid -prototype model, tumor looked like ovoid mass around $6.5 \times 5.5$ in size without neck or distant metastasis. (Fig. 1 A,B,C). Drainage and incisional biopsy were performed and pathology report was OGCT. Under general anesthesia, the tumor was excised via partial mandibulectomy and the defect was reconstructed with fibular osteocutaneous flap (Sep 18, 2003). Post resection margin was clear and final pathologic report was same as previous.
Seven months after operation, the patient felt painful swelling at the reconstructed area and tooth mobility from left first premolar to right lateral incisor (Fig. 1 D). Panorama showed a round radiolucent lesion around the incisor apex. At Contrast-enhanced paranasal sinus magnetic resonance image (PNS MRI), large round mass (diameter of $4 \mathrm{~cm}$ ) was pushing mouth floor muscles and tongue (Fig. 1 E,F). The incisional biopsy was the same as first operation, OGCT. On Jun 18, 2004, segmental mandibulectomy including the reconstructed fibular free flap and the defect was reconstructed with another fibular osteocutaneous free flap (Right leg) (Fig. 1 G,H,I). Final pathologic diagnosis of the delivered mass was OGCC instead of OGCT. After confirming the malignancy, selective neck dissection (Levels I, II) and further resection of mandible according to the pathologic margin was performed and no residual tumors were detected. No adjuvant radiotherapy or chemotherapy was performed, and the patient was followed for four years after the second operation by clinical interview, with no evidence of recurrence or distant metastasis.

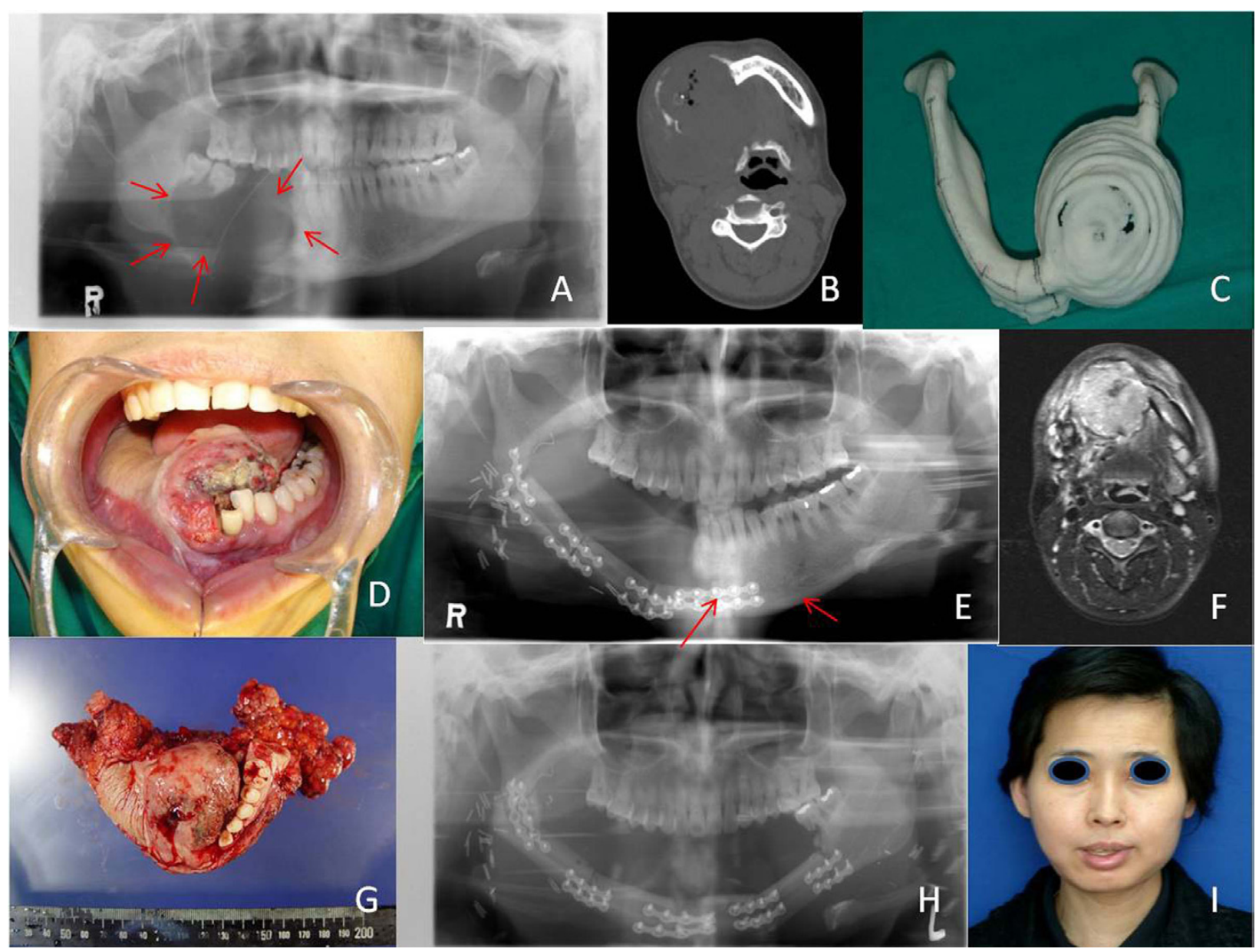

Fig. 1. Clinical and radiologic findings. A, Panorama showed central bone destruction from right first premolar to wisdom tooth. B,C, At CT and rapid -prototype model, tumor looked like ovoid mass around $6.5 \times 5.5$ in size. D,E,F, Intraoral photograph, panorama and PRI after 7 months from $1^{\text {st }}$ operation showed ulcerative swelling at the reconstructed area from left first premolar to right lateral incisor. G,H,I, Excised mass and final state of reconstructed mandible with another fibular flap. 


\section{Immunohistochemical finding}

The biopsy and surgical specimens of OGCT and its malignant form went through microscopic examination with a panel of immunohistochemical stain including; cytokeratin5 (CK5), cytokeratin14 (CK14), cytokeratin18 (CK18) and KI-67.

On microscopically findings, the proliferation of bland odontogenic cells was observed, which had a dual pattern of growth. In the area that was reminiscent of ameloblastoma, the peripheral cells were demonstrating a reverse polarity, but rather cuboidal than columnar (Fig. 2 A). The inner cells were basaloid to spindle just like the basal cell variant of ameloblastoma. There was no stellate reticulum present. The second pattern was cribriform, which was comprised of basaloid odontogenic cells forming various sizes of cysts in a large sheet (Fig. 2 B). Odontogenic epitherlial cords and islands were also present in the fibrous connective tissue between large sheets of tumor cells (Fig. 2 C). With a focus of anucleated eosinophilic ghost cell aggregates observed in the epithelial component (Fig. 2 B), the biopsy specimen was diagnosed as odontogenic ghost cell tumor (OGCT).

The specimen from partial mandibulectomy was solid, multilobulating, and encapsulated. Microscopically, the bland, odontogenic cells with basaloid or spindle shape were composing the majority of tumor as seen in the biopsy specimen. Even though ameloblast-like pattern remains here and there, sheets of mixed basaloid and spindle cells were more conspicuous. An extensive tumor area was replaced to the ghost cells which became anucleated toward center (Fig. 2 D). There was no dysplastic dentinal formation, but the presence of ghost cells and proliferating odontogenic cells could make the final diagnosis to be categorized into OGCT.

\section{$O G C T$}

Inspecting the suspected growth at the recurred mass, we could observe the same microscopic findings to the previous lesion. The histopathologic features of surgical specimen also included sheets of odontogenic cells and wide distribution of ghost cells (Fig. 2 E). However, certain area showed high cellularity, appeared, and in which the odontogenic cells were no longer blend but showing an increased nuclear-to-cytoplasmic ratio, pleomorphism, vesicular/hyperchromatic nuclei and excessive numbers of mitoses (4 6 in 1HPF) (Fig. 2 F). Accordingly, the recurred lesion was finally diagnosed as OGCC arising from OGCT. Also, we investigated immunohistochemical differences between OGCT and OGCC (Table 1). The ameloblast-like palisading cells (Fig. $3 \mathrm{~A}$ ) and spindle but not palisading cells (Fig. 3 B) were positive for CK5 \& 14. While OGCC did not show ameloblast-like cuboidal to columnar cells, pleomorphic spindle cells in OGCC demonstrated immunoreactivity for CK5\&14 (Fig. 3 C). CK18 was negative to both tumors (Fig. 3 D, E), but the labeling index of KI-67 in OGCC was much higher than in OGCT (Fig. 3 F, G) (Table 1).

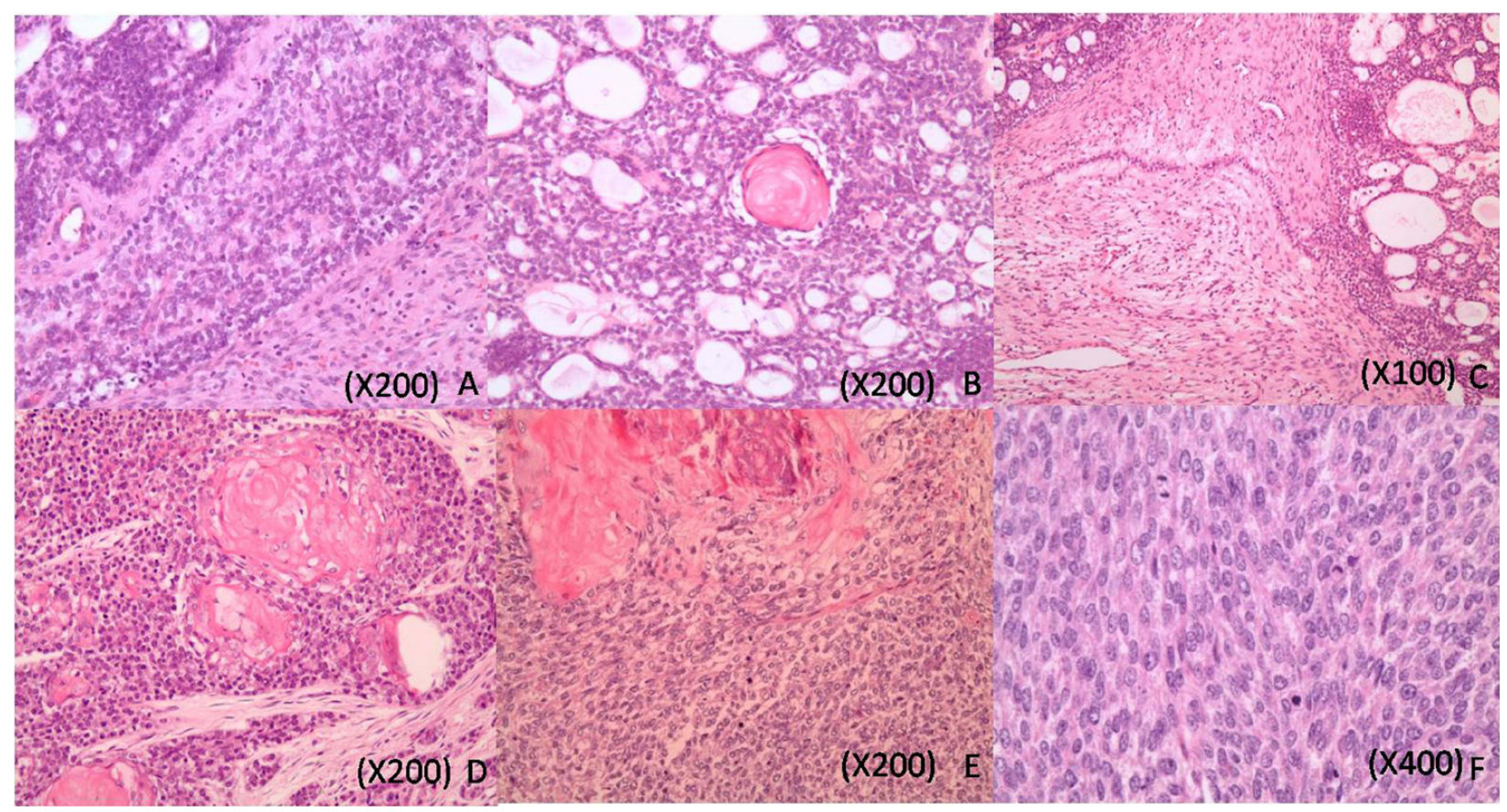

Fig. 2. Histologic slides of OGCT(A,B,C) and OGCC(D,E,F). The latter slides showed some area with high cellularity in which the odontogenic cells were no longer blend but an increased nuclear-to cytoplasmic ratio, pleomorphism, vesicular/hyperchromatic nuclei and excessive numbers of mitoses (4 6 in $1 \mathrm{HPF})$. 


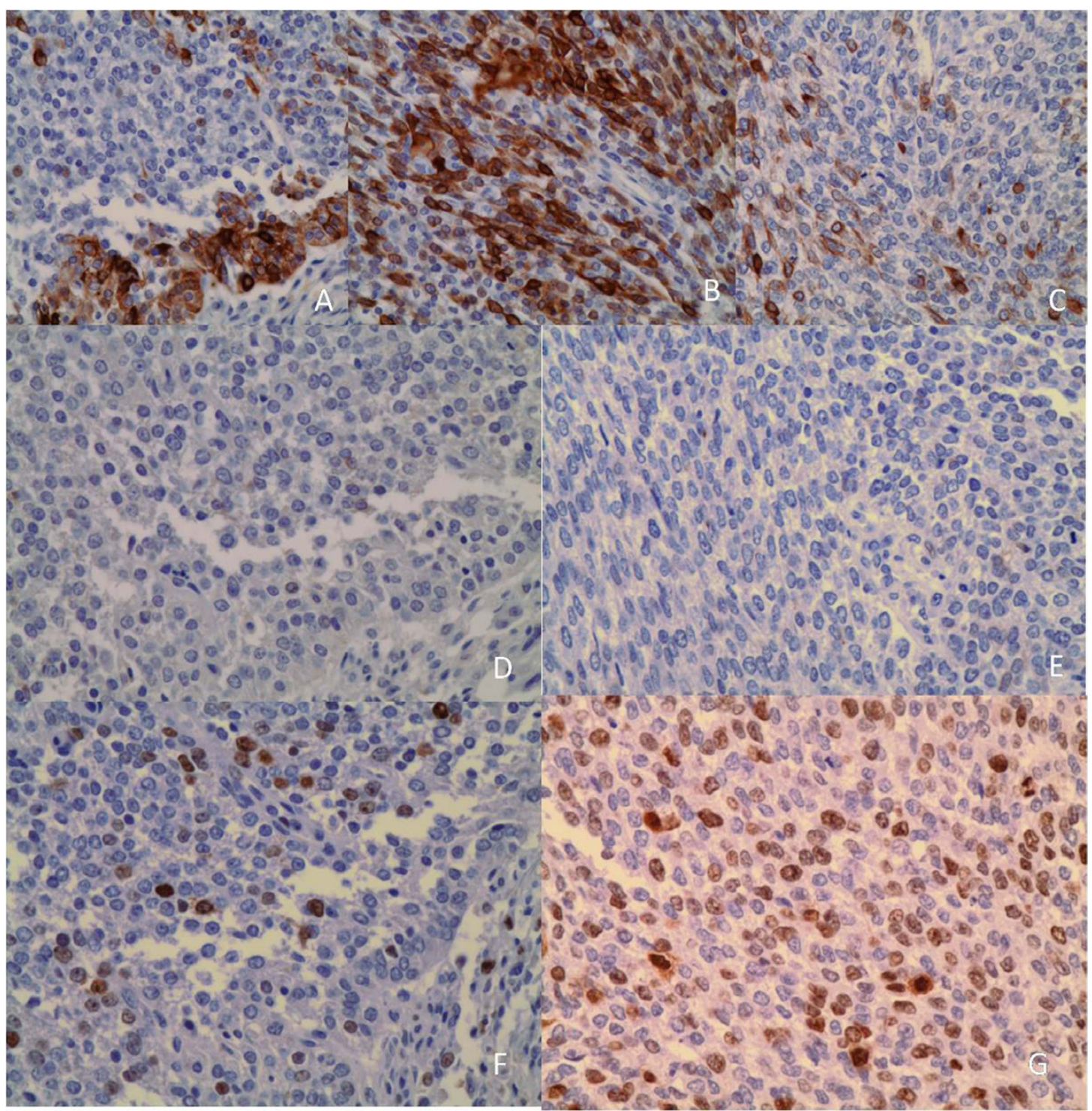

Fig. 3. Immunohistochemical studies using CK5 \& 14, CK18, and KI-67. Upper three photomicrograms are. CK5\&14 stain, OGCT(A,B) and OGCC (C). Middle photomicrograms are CK18 stains, OGCT(D) and OGCC(E). Lower photomicrograms are KI-67 stain, OGCC(F) and OGCT(G).

Table 1. Immunochistochemical findings of primary tumor (OGCT) and recurred mass (OGCC).

\begin{tabular}{|l|l|l|}
\hline & \multicolumn{1}{|c|}{ OGCT } & \multicolumn{1}{|c|}{ OGCC } \\
\hline CK5/14 & Positive in ameloblast-like spindle cells & Positive in spindle cells \\
\hline CK18 & Negative & Negative \\
\hline Ki-67 & $13.5 \%$ & $37.3 \%$ \\
\hline
\end{tabular}




\section{Discussion}

Odontogenic tumors comprise a heterogeneous group of lesions that ranges from hamartomas to benign and malignant neoplasms of variable aggressiveness. Mosqueda-Taylor(2008) pointed out how the lack of uniform criteria employed for their proper identification of odontogenic tumors (4). There are numerous names for the above described condition, including calcifying ondontogenic cyst (COC), dentinogenic ghost cell tumor (DGCT), odontogenic ghost cell tumor (OGCT) and odontogenic ghost cell carcinoma (OGCC), depending on the different terminology and classification of the group lesions. The present case was classified according to the latest criteria proposed by the World Health Organization (2). DGCT is a solid neoplastic clinicopathologic variant of $\mathrm{COC}$ and a rare odontogenic tumor. COCs account for only $1-2 \%$ of all odontogenic tumors, and only $2-14 \%$ of all COCs are solid tumors (5). DGCT recurrence had been reported in some intraosseous cases, and additional OGCCs have been documented $(6,7)$. This is an additional report of an OGCT which experienced recurrences after segmental resection of the mandible and underwent malignant transformation to OGCC (1).

Clinically, OGCC may appear as a de novo tumor or may arise as a previously diagnosed COC $(3,6-9)$. It is of interest that previous cases of OGCC are often described as multiple recurrences of COC or long-term persistent swelling followed by the onset of rapid, painful swelling before a definitive diagnosis of $\operatorname{OGCC}(5,10,11)$. This might be perceived as evidence of a transformation of a long-standing or recurrent benign process into a malignant one. In the present case, the tumor seems to have developed de novo. The clinical features of OGCC are not specific. A painful swelling in the jaws with local paresthesias is the most frequent symptom (3), and expansion of the mandible or maxilla may be noted. Of the 26 reported cases (including the present case), the ratio of males to females was 4:1, which differs from COC, which reportedly has no gender predilection. These tumors occur predominantly in middle-aged and young adults, usually within an age range of 13-72 years. This differs from benign $\mathrm{COC}$, which has a peak occurrence in the second decade of life. OGCC appears to be more prevalent in Asians (60.0\%) than in other racial groups, which is in keeping with the demographics of benign COC. Of the 26 cases of OGCC reported to date, 18 $(72.0 \%)$ were in the maxilla and seven $(28.0 \%)$ were in the mandible. The posterior maxilla is the most common site, with about $75.0 \%$ of cases located in the first permanent molar or second primary molar areas. This clear predilection of OGCC for the maxilla differs from the site distribution of benign $\mathrm{COC}$, which occurs equally in both the maxilla and mandible. In the maxilla, OGCC is not restricted to a single region, but involves an exten- sive region, corresponding to the site distribution of the COC. Fourteen cases showed destruction of the maxillary sinus with obliteration.

Histologically, OGCC is characterized by ameloblastoma-like islands of epithelial cells in a mature connective tissue stroma. Aberrant keratinization may be found in the form of ghost cells in association with varying amounts of dysplastic dentin. The primary tumor here revealed typical histological features of benign OGCT. Proliferating odontogenic epithelium with characteristic small groups or large masses of "ghost cells". These ghost cells are pale eosinophilic plump polygonal keratinized epithelial cells that have lost their nuclei; they contain a distinct intracytoplasmic keratin that preserves the outline of the cell and the corresponding previous site of the nuclei (2). In our case the primary OGCT was recurred after segmental mandibular resection and underwent malignant transformation into OGCC.

The tumor cells and ghost cells were positive for epithelial markers such as cytokeratin 5/14 and KI-67. Immunoreactivity for epithelial membrane antigen, neuronspecific enolase and p53 were also reported by other authors (12). The tumor cells were negative for CK18, smooth muscle actin, CD34, carcinoembryonic antigen, vimentin, and S-100 protein. Although the presence of ghost cells is a defining feature for the diagnosis of OGCT, these cells also may be observed in other tumors, such as craniopharyngioma, odontoma, and ameloblastic fibro- odontoma. In this study, CK5/14 was strongly expressed in the spindle cells of the OGCC, and also detected in the ameloblast-like cells/spindle cells of the OGCT. Ki-67 expression was moderate in OGCT (13.5\%), but it was more prominent in OGCC (37.3\%).

\section{References}

References with links to Crossref-DOI

1. Li BB, Gao Y. Ghost cell odontogenic carcinoma transformed from a dentinogenic ghost cell tumor of maxilla after multiple recurrences. Oral Surg Oral Med Oral Pathol Oral Radiol Endod. 2009;107:691-5.

2. Nazaretian SP, Schenberg ME, Simpson I, Slootweg PJ. Ghost cell odontogenic carcinoma. Int J Oral Maxillofac Surg. 2007;36:455-8. 3. Sun ZJ, Zhao YF, Zhang L, Li ZB, Chen XM, Zhang WF. Odontogenic ghost cell carcinoma in the maxilla: a case report and literature review. J Oral Maxillofac Surg. 2007;65:1820-4.

4. Mosqueda-Taylor A. New findings and controversies in odontogenic tumors. Med Oral Patol Oral Cir Bucal. 2008;13:E555-8.

5. Stone $\mathrm{CH}$, Gaba AR, Benninger MS, Zarbo RJ. Odontogenic ghost cell tumor: a case report with cytologic findings. Diagn Cytopathol. 1998;18:199-203.

6. Daniels JS. Recurrent calcifying odontogenic cyst involving the maxillary sinus. Oral Surg Oral Med Oral Pathol Oral Radiol Endod. 2004;98:660-4.

7. Castro V, Knezevic MR, Barrero MV, Diaz JM, Baez O, Castellano JJ. The central (intraosseus) epithelial odontogenic ghost cell tumor: Report of a case. Med Oral. 1998;3:101-106.

8. Kasahara K, Iizuka T, Kobayashi I, Totsuka Y, Kohgo T. A recurrent case of odontogenic ghost cell tumour of the mandible. Int J Oral Maxillofac Surg. 2002;31:684-7.

9. Ledesma-Montes C, Gorlin RJ, Shear M, Prae Torius F, MosquedaTaylor A, Altini M, et al. International collaborative study on ghost 
cell odontogenic tumours: calcifying cystic odontogenic tumour, dentinogenic ghost cell tumour and ghost cell odontogenic carcinoma. J Oral Pathol Med. 2008;37:302-8.

10. Roh GS, Jeon BT, Park BW, Kim DR, Hah YS, Kim JH, et al. Ghost cellodontogenic carcinoma of the mandible: a case report dem onstrating expression of tartrate-resistant acid phosphatase (TRAP) and vitronectin receptor. J Craniomaxillofac Surg. 2008;36:419-23.

11. Grodjesk JE, Dolinsky HB, Schneider LC, Dolinsky EH, Doyle JL. Odontogenic ghost cell carcinoma. Oral Surg Oral Med Oral Pathol. 1987;63:576-81.

12. Folpe AL, Tsue T, Rogerson L, Weymuller E, Oda D, True LD. Odontogenic ghost cell carcinoma: a case report with immunohistochemical and ultrastructural characterization. J Oral Pathol Med. 1998;27:185-9.

\section{Acknowledgement}

This work was supported by: the Korea Health R\&D project (A084152), granted by Ministry of Health and Welfare, Republic of Korea. 